\title{
40 OPERATIONAL DESIGN IN VO SUPPLY NETWORKS CREATION
}

\author{
Cathal Heavey, PJ Byrne, Paul Liston, James Byrne \\ Enterprise Research Centre,University of Limerick, cathal.heavey@ul.ie \\ IRELAND
}

\begin{abstract}
Outsourcing is a major driver in the growth of Virtual Organisations (VOs) in the manufacturing domain. These outsourcing networks can be classified as Virtual Organisations (VOs) as they are created from different organisational entities for a specific purpose and exist for a specified period of time. The electronics industry is in the vanguard with a projected $23 \%$ of electronics manufacturing forecasted to be outsourced in 2007. The process of establishing these VOs is known in the industry as the Request for $X$ (RFX) process. This paper argues that in the creation of VO supply networks, supply network design support is required.
\end{abstract}

\section{INTRODUCTION}

It is estimated that in total $75 \%$ of the EU GDP and $70 \%$ of employment in Europe is related to manufacturing (Flegel, 2004), Outsourcing networks are a defining characteristic of modern manufacturing and uptake by companies of this manufacturing strategy is predicted for strong growth in the future. For example, in 2003 , about $15 \%$ of all electronics manufacturing was outsourced. That percentage is predicted to grow steadily into the future with a projected $23 \%$ of electronics manufacturing outsourced by 2007 (Carbone, 2005). Growth in outsourcing is also predicted across several other sectors. For example, in the pharmaceutical industry the value of the drug discovery outsourcing market is reportedly set to increase at a rate of $15 \%$ from a 2005 figure of $\$ 4.1$ billion to nearly $\$ 7.2$ billion by 2009 (Kalorama Information, 2005). Clearly, this structural adjustment of industry will require manufacturing enterprises across Europe to adapt.

Outsourcing networks (or virtual networks) typically link highly innovative but deverticalized lead firms (OEMs) with sets of highly functional suppliers who provide a wide range of production-related services (Sturgeon, 2000). These networks are highly flexible systems characterized by fluid relationships with shortterm contracts between participants within the network. The process of establishing a contact between two enterprises in a virtual network is known collectively as the Request for $\mathrm{X}$ (RFx) process, with RFx representing Request for Information (RFI), Request for Quotation (RFQ), etc. In this process a customer (i.e., Original Equipment Manufacturer (OEM), Contact Manufacturing (CM) or sub-supplier), also denoted as a buyer, will issue a RFQ to suppliers and typically request a response to the RFQ within weeks.

Current literature pertaining to VOs generally examines obstacles to the creation and execution of VOs and presents innovative methodologies for tackling these issues. For example, Bosch-Sijtsema (1997) studied possible communication difficulties faced by VOs and identified five boundaries which both create and 
inhibit learning and communication. These are time, space, diversity, structure and distribution and are all characteristics of a VO. Meanwhile, the CONOISE project (Norman et al., 2003) examined methodologies for the initial formation and continued management of VOs in dynamic, open and competitive environments. Due to the often dispersed nature of VOs they can be heavily reliant on communication technology. Consequently, VO related literature maintains a focus on new technologies which can support the continued operation of such organisations (Kamio et al., 2002). This paper examines the formation of VOs but emphasises the importance of streamlining this task into standard business practice plus the importance of including operational detail at the design phase. It is argued that supply network design support needs to be embedded into the RFx process and that this could act as a catalyst to increase VO creation and participation of SMEs in VOs.

The paper is structured as follows. Descriptions of three VO supply networks obtained from field work and the operational design issues faced at VO creation time are given in Section 2.0. Using one of these VOs, Section 3.0 illustrates how operational design can be supported using simulation. Finally, Section 4.0 gives requirements of a tool that would encompass operational design support for VO supply network creation.

\subsection{EXAMPLE SUPPLY NETWORKS}

Research has been carried out into the use of simulation to support contract costing for companies in the electronics outsourcing sector (Byrne et al., 2005; Liston et al., 2006). As part of this research, field research was conducted in companies operating in a variety of supply chain echelons in the electronics sector, more specifically: two Original Equipment Manufacturers (OEMs), two first tier Contract Manufacturers (CMs), one second tier CM, one Third Party Logistics Provider (3PL) and two Fourth Party Logistics Providers (4PLs). In this analysis, three instances of VO supply networks were identified and studied. These instances are only a sample of the many types of VO supply networks found in practice.

\subsection{Contract Manufacturer}

Bridgefield (2003) gives the following description of a Contract Manufacturer (CM): "A third party that performs one or more production operational for a manufacturer who will market the final item under their own name. They often charge on a per-piece or per-lot basis for the labour required for their services while using components or materials supplied and owned by the final item manufacturer." Contract manufacturers can be further categorised depending on their positioning within a supply chain. The phrases 'First Tier', 'Second Tier', etc. are used to denote these positions. When responding to a $R F Q$ a $C M$ will very often be required to develop a VO supply network. An example RFQ obtained in a field study was where an OEM decided to outsource all of its packaging activities and issued a RFQ to this effect. To respond to this RFQ the CM needed to develop and cost a solution where it would be responsible for managing all material, procurement, warehousing, inventory, IT, logistics and quality activities. This involved developing a VO supply network as illustrated in Figure 1. To develop such a solution the CM needed to 
address in short time frame (6 weeks was given to respond to the RFQ) a range of operational design issues typically encountered in developing a supply network. In this example qualifying RFQs went on to participate in a reverse auction.

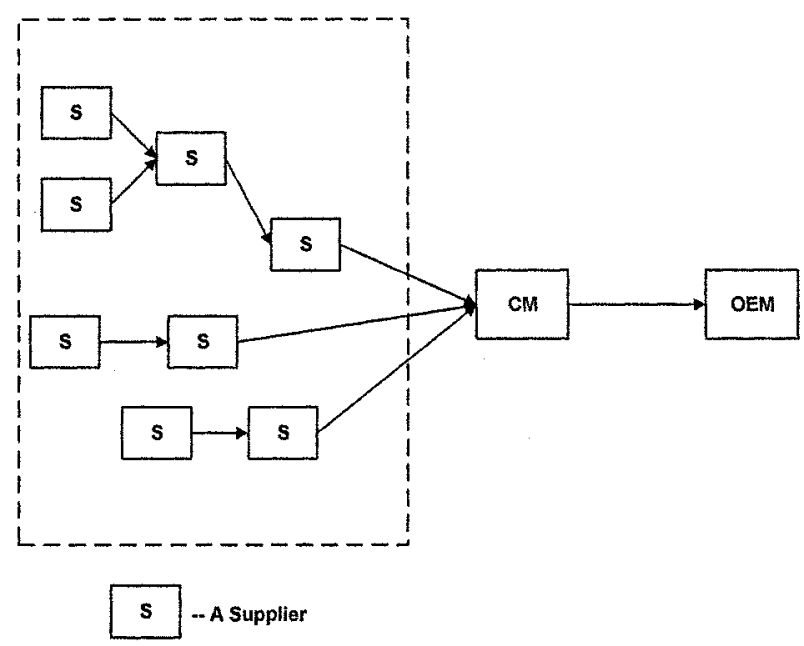

Figure 1 - CM VO supply network example

\subsection{Supplier Sourcing Company}

This example involves a company focused on sourcing suppliers in response to a RFQ. In a number of instances this involves developing a VO supply network in order to supply a product or component. One common reason why a VO supply network is needed is that a single company with all the technological capabilities required may not exist. Another probable reason may be that even if one company is capable of completing all tasks, there may be other companies who can complete certain tasks either more competently, more economically or both.

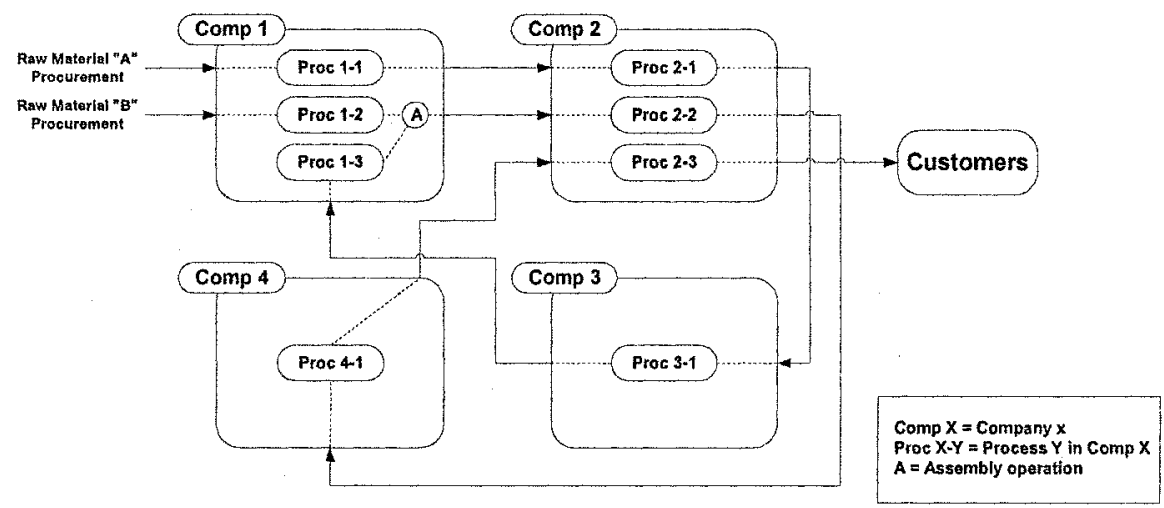

Figure 2 - Process steps for component supplied by Supplier Sourcing Company

An example encountered in the field study was a VO supply network designed to supply a component as illustrated in Figure 2. Figure 2 presents the process steps 
and their sequence for the manufacture of the component. Four different manufacturing companies were involved in two countries with significant transportation of the component. Note from Figure 2 that the component parts visit company 1 three times and company 2 three times. Again, operational design issues need to be addressed in the creation of this VO supply network.

\subsection{Virtual Breeding Environment Supply Network}

The third example is an open network of companies in the Shannon region of Ireland that was established in January 1999. The network was established to provide more business opportunities for the member companies primarily achieved through joint marketing initiatives such as exhibitions, tradeshows, and advertising and greater profile awareness. This network is best described as a regional Virtual Breeding Environment (VBE) (Afsarmanesh, Camarinha-Matos, 2005) with individual members currently creating supply networks, within and outside the network, on a global scale. A goal of the network is to increase the capability of the network members to collaborate in response to RFQs.

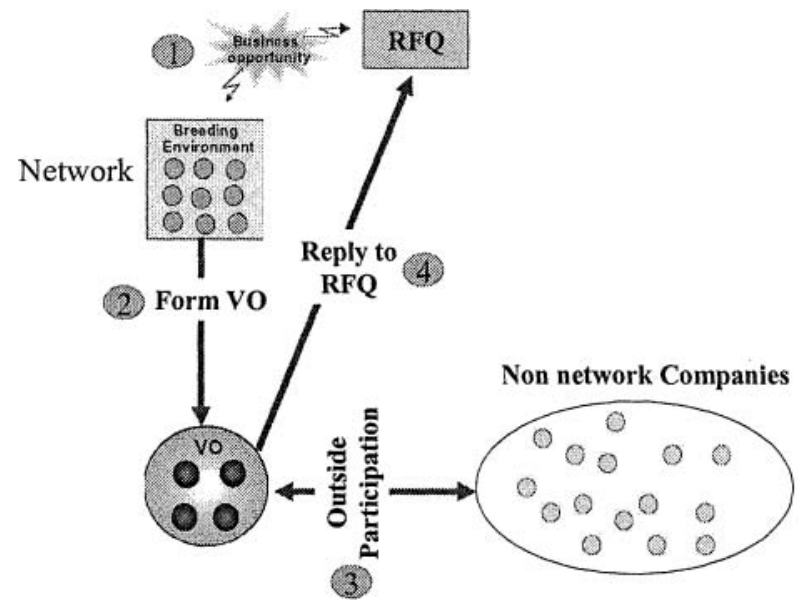

Figure 3 - VBE scenario

Figure 3 illustrates a "to-be-situation" with the network. A RFQ is received either by the network organization or a member of network (see label 1 Figure 3). A real example would be a RFQ for the design, manufacture and product life cycle management of a family of products. Members of the network will form a VO to bid for this work (see label 2 Figure 3). Capabilities in the network would allow a member to carry out product design, another member to carry out plastic moulding, test, de-bug and repair by another member and a 3PL member could coordinate logistics. As shown in label 3, participation of outside companies, who maybe located globally, will typically also be required. Past work by the open network identified many barriers to reach this "to-be-situation". One of these barriers is the lack of supply network design capabilities in developing, costing and selling a VO supply network solution to the customer. 


\subsection{OPERATIONAL DESIGN SUPPORT FOR VO CREATION}

This section reports on work carried out to validate the use of simulation to support VO supply network development and costing for a Contract Manufacturer (CM) as described in sub-section 2.1 (Liston et al., 2006). The CM was selected from the three other VOs encountered, as it is widely found in industry. Also, VOs created by a CM will have a relatively stable structure compared to the two other VOs reviewed in Section 2, reducing the complexity of developing support tools. A model (see Figure 4) was built using eM-Plant on the scenario presented in Figure 1.

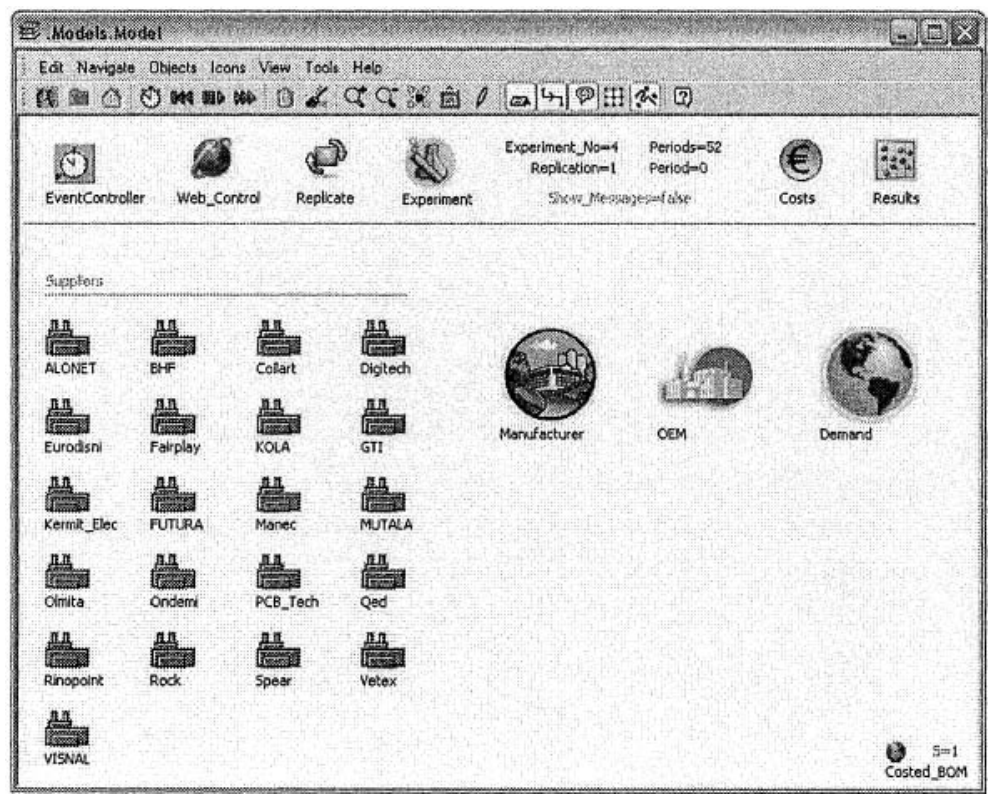

Figure 4 - CM simulation model

The model contains extensive operational details as indicated by Figure 5 .

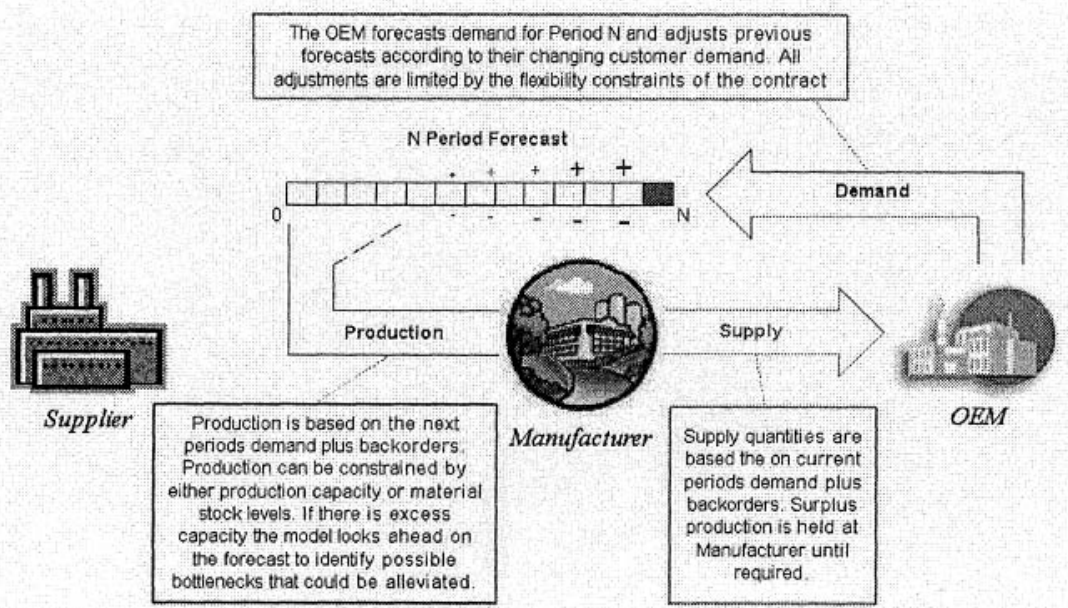

Figure 5 - Model interaction between Manufacturer and OEM 
The simulation sequence begins with demand being communicated to the OEM frame where it is used to generate a continuous thirteen period forecast for the CM. Figure 5 shows how this demand is translated back to the CM and how the CM responds. The OEM frame also contains the information concerning flexibility constraints as stipulated in the RFQ. These flexibility constraints allow a customer $(\mathrm{OEM})$ to increase or decrease the order quantity by a limited amount depending on the time left to the due date (a more comprehensive discussion on such contract terms can be found in the work of Tsay et al. (1999) or Bassok et al. (1997)).

To illustrate how simulation can assist in VO creation, some sample output from the above model is depicted in Figure 6. This graph shows the minimum, maximum and average values for unit cost of a component using eleven different VO scenarios. The range at each design point in Figure 6 is obtained by running each design point under different random number streams ( 15 in this case). This is done to mimic future uncertainties. If the unit cost of a component is set by the $\mathrm{CM}$ at the price level shown in Figure 6, there is a risk of losing money if VO configurations 6 , 7, 10 and 11 are used. This example briefly illustrates the type of operational design issues that need to be addressed when responding to an RFQ.

The model together with extensive experimentation on the following were presented to CMs: (i) Supplier Selection; (ii) The pattern of sales demand; (iii) Flexibility constraints specified in the RFQ; (iv) Capacity and (v) Inventory policies. Feedback from the companies was positive; however, feedback highlighted the need to develop a tool that is better integrated into the RFQ process.

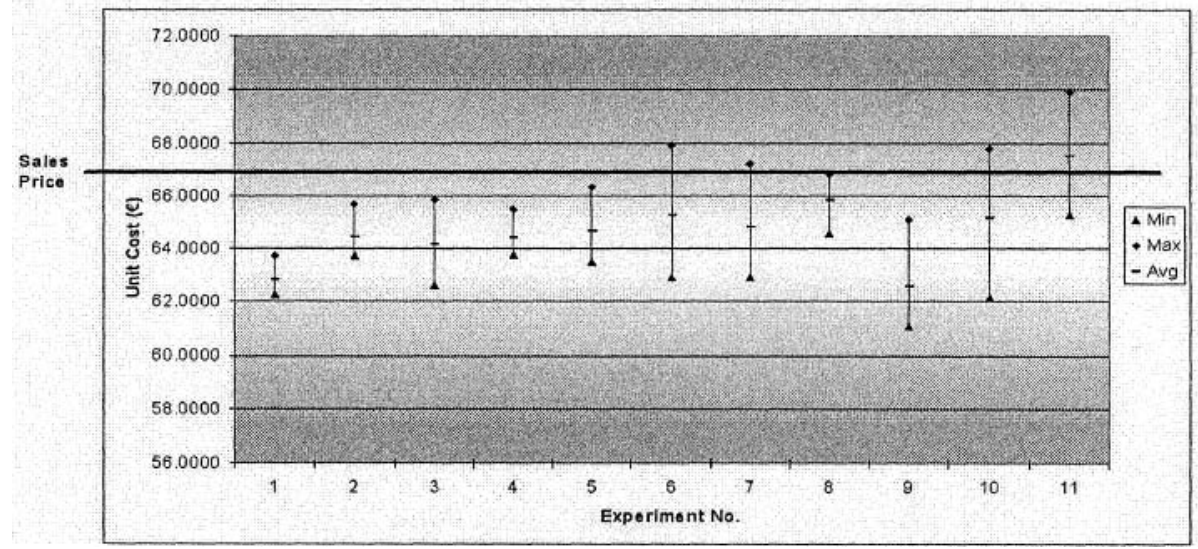

Figure 6 - Range of Unit Cost Values for each Experimental Run

\section{TOWARDS SUPPLY NETWORK VO CREATION SUPPORT TOOLS}

RFx-based procurement tools, a segment of the Supplier Relationship Management software sector, are used for the sourcing, qualification and choosing of suppliers. These tools have the features of: sending out a request for information, sending out a request for quotation, setting up an on-line auction, and scoring features to choose a 
supplier(s) for a particular product. These tools are controlled from the buyer side. Once the supplier has been chosen, contract management tools can be used to create the contract between the supplier and purchaser, and to manage the contract throughout its lifecycle until termination. Separate contract management tools can be used on both the buyer and seller sides. A sample of RFx-based procurement tools are listed in Table 1. Also, listed in Table 1 are the main features of these tools. These tools are all web-based facilitating communication with suppliers. None of the tools surveyed include operational design support for VO supply network creation. It is clear that any operational design support tools developed will need to integrate with RFx existing procurement tools or incorporate their capabilities to facilitate information gathering and communication with suppliers.

The requirements, ascertained so far, of a software application that will support operational design for VO supply network creation are as follows:

1. The application should provide the ability to evaluate different VO supply chain solutions and in these evaluations capture operational related costs.

2. The software must integrate with existing RFx procurement tools or incorporate their communication and information gathering capabilities.

3. For decentralised (or VBE) instances of VO creation the application should facilitate collaborative design. This feature may not be important in centralised instances of VO creation, such as the CM case.

4. The application would need to facilitate rapid analysis of VO scenarios, as the time to respond to a RFQ is typically short.

5. The application should require a low level of expertise to use. For example, resources required to develop the simulation models described in Section 3.0 would not be justifiable for a tool used on a continuous basis.

A prototype tool for the CM instance is being developed and evaluation of this tool by companies is planned.

Table 1: Sample RFX-based Procurement Tools: vendors/tools included and identified features

\begin{tabular}{|c|c|c|c|}
\hline \multicolumn{4}{|c|}{ RFX-based Procurement Tools } \\
\hline \multicolumn{4}{|c|}{ Vendorsf Tools included in the Survey } \\
\hline ASC Bids & PCBspecialist & FreeMarkets & EBreviate \\
\hline Ariba & Procurí & Frictionless & Emptoris \\
\hline B2emarkets & PurchasePro & lasta & Silanta Technologies \\
\hline Bellwether RFQ module & Tradestone & SAP RFQ and Auctions & XTO software \\
\hline Commerce One Source & Upside RFX & Epiq & \\
\hline Overall Feafures Identified & \multicolumn{3}{|c|}{ Description of Features } \\
\hline RFx Creation & \multicolumn{3}{|c|}{ Questionnaires, templates, attachment of files, Tracking of Ammendments, automation (wizards) } \\
\hline Collaboration/Communication & \multicolumn{3}{|c|}{ Online Message boards, email, negotiation window } \\
\hline Reverse Auction & \multicolumn{3}{|c|}{ Multiple Attributes, Countdown Clock, Pricing Curves, Savings Charts } \\
\hline Supplier Scoring & \multicolumn{3}{|c|}{ Weighted Questions, Optimisation Capabilities, Weighting of evaluators, side-by-side comparisons } \\
\hline Architectural Features & \multicolumn{3}{|c|}{ Fully Web-based, Centralised Repository/Database } \\
\hline Monitoring and Reporting & \multicolumn{3}{|c|}{ Online queries/reports, ability to export reports to other software tools } \\
\hline
\end{tabular}

\section{CONCLUSIONS}

Outsourcing is a major driver in the creation of VO supply networks. The process by which VO creation takes place is the RFx process. Three instances of VO supply networks were described in the paper, spanning from a highly centralized mode (i.e., 
$\mathrm{CM}$ example) of VO creation to a decentralized or network mode of VO creation. For all instances operational design support is lacking for VO creation. In relation to the CM it was illustrated how simulation can be used to assist VO creation. In regard to decentralized or network VO creation many barriers exist in increasing collaboration among network members. In relation to VO supply networks this paper argues that operational design support tools need to be developed and embedded into the RFX process. Current research is being undertaken in developing tools for the CM VO creation case.

\section{Acknowledgments}

This work was conducted as part of a collaborative project between the University of Limerick and the NITL, Dublin Institute of Technology, and is funded by Enterprise Ireland under project ref. no. TD/03/411 (SIMCT).

\section{REFERENCES}

1. Afsarmanesh, H; Camarinha-Matos, L. M.: A framework for management of virtual organizations breeding environments. In Proceedings of PRO-VE'05 - Collaborative Networks and their Breeding Environments, Springer, pp. 35-48, Valencia, Spain, 26-28 Sept 2005.

2. Bassok, Y., A. Bixby, R. Srinivasan and H. Z. Wiesel. "Design of component-supply contract with commitment revision flexibility." IBM J. Res. Dev., 1997, 41(6): 693-704.

3. Bosch-Sijtsema, P.M.: Crossing Learning Boundaries. The Utility related Virtual Organisation ISES. Newsletter of virtual-organization.net in VoNet 1, 1997, 5 (Dec.). Electronic journal: www.virtualorganization.net

4. Bridgefield. "Bridgefield Group ERP/Supply chain Glossary", 2003. http://www bridgeficidgroup.com/glos 2. htm, Accessed on $23^{\text {th }}$ September, 2005.

5. Byrne, J., C. Heavey and P. Byrne. "Requirements for a Simulation-Based Tool to Aid in the ContractCosting Process". In Proceeding of $18^{\text {th }}$ International Conference on Production Research, University of Salerno, Italy, July 31 - Aug 4, 2005.

6. Carbone, J. "Worldwide Outsourcing Rises", 2005. http://www purchasing com/article/CA501253.html, Accessed on 12 $2^{\text {th }}$ December, 2005.

7. Flegel, H. "Manufacturing a Vision for 2020: Report of the High Level Group." 2004. http:/europa.eu.int/comm/research/industrial technologies/pdf/manufuture, vision en.pdf, Accessed on March $20^{\text {th }}, 2006$.

8. Kalorama Information. "Outsourcing in Drug Discovery, 2nd Edition", 2005. http $/$ www prnewswire.com/cgi-bin/stories pl?ACCT $=109 \&$ STORY $=/$ www/story/03-0220060004312261\&EDATE=, Accessed on March $24^{\text {th }}, 2006$.

9. Kamio, Y., F. Kasai, T. Kimura, Y. Fukuda, I. Hartel and M. Zhou. "Providing Remote Plant Maintenance Support through a Service Virtual Enterprise". In Proceeding of GLOBEMEN (Global Engineering and Manufacturing in Enterprise Networks), Helsinki, VTT, 2002, 195-205.

10.Liston, P., P. J. Byme and C. Heavey. "An Evaluation of Simulation to Support Contract Costing." Computers \& Operations Research, 2006 In Press, Corrected Proof, Available online 28 Feb 2006.

11.Norman, T. J., A. Preece, S. Chalmers, N. R. Jennings, M. M. Luck, V. D. Dang, T. D. Nguyen, V. Deora, J. Shao, W. A. Gray, and N. J. Fiddian, "CONOISE: Agent-based formation of virtual organisations," in Research and Development in Intelligent Systems XX: Proceedings of AI2003, the Twenty third International Conference on Innovative Techniques and Applications of Artificial Intelligence, 2003, 353-366.

12.Sturgeon, T. J. "How Do We Define Value Chains and Production Networks." MIT IPC Globalization Working Paper 00-010, 2000.

13.Tsay, A. A., S. Nahmias and N. Agrawal. "Modeling Supply Chain Contracts: A Review". Quantitative models for supply chain management. S. Tayur, R. Ganeshan and M. Magazine, Kluwer Academic Publishers, Norwell, MA.: 1999, 299-336. 